\title{
Service Recovery: An Integrative Framework and Research Agenda
}

\author{
Yves Van Vaerenbergh \\ KU Leuven, Belgium \\ Chiara Orsingher \\ University of Bologna, Italy
}

\begin{abstract}
Author note
Yves VAN VAERENBERGH, KU Leuven, Belgium, yves.vanvaerenbergh@kuleuven.be Chiara ORSINGHER, University of Bologna, Italy, chiara.orsingher@unibo.it
\end{abstract}

Correspondence concerning this article should be addressed to Yves Van Vaerenbergh, Department of Marketing, KU Leuven, Warmoesberg 26, 1000 Brussels, Belgium Contact: yves.vanvaerenbergh@kuleuven.be

\section{Acknowledgements}

The authors would like to sincerely thank Academy of Management Perspectives' editor Timothy M. Devinney as well as two anonymous reviewers for their constructive feedback. We would also like to thank Simon Hazée for his helpful comments and suggestions. The first author gratefully acknowledges financial support from the Impulse Fund, KU Leuven (IMP/14/006). 


\title{
Service Recovery: An Integrative Framework and Research Agenda
}

\begin{abstract}
Service recovery captures the organizational actions of seeking and dealing with a failure in the service delivery. Although many studies have examined the outcomes of organizational efforts in managing service recovery, there is a lack of a comprehensive framework embracing the focal constructs, the causal relationships, the interdisciplinarity, and the levels of theory in service recovery. In this paper we synthesize theoretical and empirical studies examining the operations, marketing, and human resources management views on service recovery, offering three contributions to the literature. First, we develop an interdisciplinary and multilevel framework linking organizational investments in service recovery to organizational, employee, and customer outcomes, within and across levels of theory. Second, we integrate conceptual and empirical propositions from previously separate research. Third, we offer scholars a research agenda highlighting several issues that are in need of interdisciplinary research on service recovery.
\end{abstract}

Keywords: Service Quality, Service Failure, Service Recovery, Customer Complaints, Complaint Management, Research Synthesis 
Service Recovery: An Integrative Framework and Research Agenda

Service organizations often need to handle the complaints that customers file when a service failure happens. Service recovery, which generally refers to the actions a service provider takes in response to customer complaints (Grönroos, 1988), is thus an integral part of the organization's service activities. Although researchers have studied service recovery issues for over four decades (e.g. Kendall \& Russ, 1975), organizations are still struggling with various aspects of service recovery management. The 2013 U.S. customer rage survey, for example, indicates that customer satisfaction with service recovery in 2013 is no higher than that reported by the 1976 White House Study (CMCC, 2013). Moreover, many organizations do not seem to make use of customer complaints to improve the processes that caused the service failure, and fail to support adequately their employees in dealing with complaining customers (Michel, Bowen, \& Johnston, 2009). Managers also tend to perceive service recovery as a cost rather than an investment (Rosenbaum, 2015), and have no clear information on its impact on firm performance. As a result, the yearly revenue at risk to U.S. business because of a poor service recovery is estimated around $\$ 76$ billion (CCMC, 2013).

This situation is paradoxical. On the one hand, service recovery is often considered as one of the most mature research areas in service management literature (Kunz \& Hogreve, 2011), with researchers offering insights on how to manage service recovery effectively. On the other hand, the large number of organizations still struggling with service recovery management (Michel, et al., 2009) suggests that this significant body of research has had relatively little impact on organizational service recovery policies and practices. The purpose of this paper is to take a step in addressing this paradox by synthesizing the theoretical and empirical knowledge on service recovery gained from the extant research on this subject, and integrate this knowledge into an overall framework. 
Two factors suggest the need for conceptual integration and for a unifying framework of service recovery. First, the inspection of prior research reveals that studies are often conceptualized within a specific discipline, focusing on a set of very specific questions. Operations management researchers focus on understanding how organizations can develop service recovery systems (e.g. Smith, Karwan, \& Markland, 2009), human resource management researchers focus on understanding how organizations can support their employees in the task of dealing with complaining customers (e.g. Bowen \& Johnston, 1999), and marketing management researchers focus on understanding how customers react to the organization's service recovery efforts (e.g. Smith, Bolton, \& Wagner, 1999). Such disciplinary thinking is mainly useful for organization science, but runs the risk of not being able to consider service recovery as a set of integrated concepts and theories. We think the time has come to increase researchers" awareness that "real-world problems do not come in disciplinary-shaped boxes" (Jeffrey, 2003, p. 539), and to offer an integrated view of how conceptual and empirical propositions on service recovery affect the organization as a whole.

Second, an examination of the research tradition of service recovery management scholars reveals that researchers in operations management have approached the subject from a macro perspective, providing suggestions about the actions that need to be done at the macro (i.e. firm) level. Human resource management and marketing researchers have approached service recovery mainly from a micro perspective, in an effort to understand individual employee and customer perceptions and behavior. Tackling real-world organizational problems, however, requires an integrated approach that not only transcends the different disciplines, but also that cuts across the different levels of the organization. As Kozlowski \& Klein (2000) note, researchers can have an impact on organizational policies when conceptualizing and assessing significant phenomena at multiple levels simultaneously, taking into account both top-down and bottom-up processes. Against this backdrop, the lack 
of a unified view on service recovery might help explaining why many organizations still struggle with managing service recovery effectively.

This paper provides three fundamental contributions. First, this paper approaches service recovery from a truly interdisciplinary background. We review insights from prior and current research on this subject in the different disciplines, draw connections between streams of research that are not typically cited together and that appear in journals that belong to different areas, and take a more problem-oriented rather than discipline-oriented view on service recovery. With this effort, we break free from the 'disciplinary boxes' (Alvesson \& Sandberg, 2014) that typically exist within the domain. We propose a view of service recovery management that allows to make broader connections and framing of this phenomenon, and thereby open up new ways of seeing, researching, and acting on service recovery. As such, this paper answers the recent calls for more interdisciplinary service research (Ostrom, Parasuraman, Bowen, Patricio, \& Voss, 2015; Subramony \& Pugh, 2015).

Second, by reorganizing in a multilevel framework the relevant literature, we offer a view of the key themes in service recovery within and across macro and micro levels, and show how these themes are related rather than disassociated (Michel, et al., 2009). We believe that such effort can reduce the discrepancy between research that resides at the micro level (e.g., customers' justice perception of the recovery actions) and the one that resides on a macro level (e.g., service recovery systems). Such effort might help reducing the difference between academic focus on either the micro or the macro level and the managerial need about the strategic implications of findings that traverse multiple echelons of the organization (Wong, 2016). Finally, we propose an agenda for future research in this important domain of service management.

\section{Method}


We employed a large-scale integrative review method. Integrative reviews include research using various methodologies to serve a wide range of purposes: to define concepts, to review theories, to review evidence, and to analyze methodological issues (Broome, 1993). The inclusive sampling frame combined with the multiplicity of purposes aimed to build a comprehensive picture of concepts, theories, and issues of importance to service recovery. The entire review process involved three stages.

First, we run a literature search of articles published in the Web of Knowledge ${ }^{\circledR}$ database using the keywords service recovery, complaint handling, and complaint management. In addition, we conducted issue-by-issue searches of the following service journals in order to retrieve additional studies on service recovery: Journal of Service Research, Journal of Service Management, Journal of Services Marketing, Managing Service Quality, Service Business: An International Journal and Service Industries Journal. Finally, we used an ancestry approach in which we searched references of studies we identified as relevant to the current review. This process generated more than 500 articles for review.

Next, we evaluated the literature. An article was deemed appropriate for inclusion if (i) the paper specifically examines a firm's response to a customer complaint, excluding articles that examine only customer reactions to service failures, or reasons why customers complain; and (ii) the paper is published in an academic journal that underwent a peer review process, thereby excluding conference proceedings. Articles were first marked with a check (if criteria (i) and (ii) were fulfilled), a question mark (if we were unsure), or unmarked (if criteria (i) and/or (ii) were not fulfilled). Next, we read all articles receiving a question mark, evaluated their pertinence and their informational value, and either checked or unmarked them. Finally, we labeled articles as solely relying on one of the three disciplines examining service recovery, or as adopting an interdisciplinary approach. We retained 360 articles published in 96 different journals, between 1988 and 2014. The majority of papers (75.3\%) took a 
marketing perspective to studying service recovery, while only a minority took a human resource management $(11.1 \%)$, operations management $(9.4 \%)$, or interdisciplinary perspective $(4.2 \%)$.

Our final stage involved the actual literature analysis. First, we determined an overall classification scheme based on the level of analysis (firm, employee or customer) used to tackle service recovery issues. Second, we extracted concepts and research findings and organized them into the classification scheme. Third, we identified relationships between concepts pertaining to a single level of analysis or between different levels of analyses, and visually displayed their logical chain.

\section{An Integrative Framework of Service Recovery}

The phenomenon we are attempting to understand in this synthesis is whether the investments in service recovery lead to firm performance, and what are the processes that underlie this phenomenon. Service recovery represents the set of actions an organization takes to re-establish customer satisfaction and loyalty after a service failure, to ensure that failure incidents encourage organizational learning and process improvements, and to train and reward employees for this purpose (Michel, et al., 2009, p. 267). This definition points to the idea that concepts and theories from different disciplines (marketing, operations management, and human resources management) occurring to different entities (the organization, the employees, and the customers) are necessary to capture the range of action of service recovery.

In this paper, we distinguish between two levels of theory: a macro level, which generally refers to issues that transcend the differences among individuals, and a micro-level, which refers to understanding individual actors' perceptions, affect, and behaviors (Kozlowski \& Klein, 2000). In service recovery literature, macro-level researchers mainly considered the firm as unit of analysis. One notable exception is De Jong and De Ruyter (2004), who 
examined service recovery performance at the branch level. Given the lack of research focusing on this level, we collapsed both levels of analysis (firm and branch) in an overall macro level of theory. At this level, organizations take decisions on the structural dimensions of their recovery system by defining its properties and its operating processes. These decisions are meant to produce effects on firm-level outcomes such as process improvements, collective employee and customer outcomes, and firm performance. Micro-level researchers considered either individual employees, individual customers, or the interaction between both as unit of analysis. Research at this level generally shows that individual employee attitudes and behaviors shape their abilities to resolve service failures, and individual customers' justice perceptions shape their evaluation of the employees' ability to handle complaints.

Single level processes however, are not sufficient to understand the integrative nature of service recovery. Employees and customers are embedded within an organizational context, thus, we also consider how the concepts and processes that are involved in service recovery are linked across levels (Kozlowski \& Klein, 2000). As an example, organizations might differ in the importance they attach to customer complaints, and therefore in the investments made in the recovery system: While some organizations have a strong recovery system, other put less emphasis on developing such systems (Smith \& Karwan, 2010). Individual employees thus differ in the degree to which they are and feel supported in their task of dealing with complaining customers, depending on the strength of the recovery system in their organization. Similarly, customers who voice a complaint might receive a different response depending on the extent to which the organization invested in the service recovery system.

Bottom-up process are also likely to emerge. Concepts that have their theoretical foundations in the cognition, affect, behavior, and characteristics of individual employees might develop properties that manifest at higher levels. For example, interactions among 
employees and customers, in an attempt to resolve customer complaints, might yield firmlevel process improvements, but also yield refinements of the service recovery system itself. This suggests that a service recovery system should be regarded as a dynamic system that improves over time. Individual customers that are satisfied with the organizations' recovery efforts might result in firm-level customer satisfaction and high retention rates. Thus, collective customer outcomes emerge from individual customer outcomes.

The result of our review is a multilevel, interdisciplinary framework that outlines the concepts and the relationships that are involved in the understanding of how service recovery investments affect firm performance (see Figure 1). The framework has not been tested in its entirety, but relationships between parts of it have been empirically validated.

\section{[Insert Figure 1 here]}

The remainder of this paper presents in detail the support for the relationships outlined in the service recovery framework. We first discuss the relationships occurring at the macro level (i.e. firm level). Afterwards, we discuss micro-level relationships at the employee and the customer level. Then, we detail the multilevel relationships and microfoundations reported in the service recovery literature. We conclude with a research agenda that specifies further constructs and relationships within and across levels of analyses.

\section{Macro-level relationships}

\section{The Service Recovery System}

Service organizations concerned about complaint management benefit from investing in a recovery system. Only few studies address how service organizations should design such a system. Drawing from research on organizational structures, Smith, Karwan and Markland (2009) identify and operationalize seven distinct structural dimensions of an effective service recovery system: accessibility, formality, decentralization, comprehensiveness, human intensity, system intensity, and influence. We detail these seven dimensions next. 
Accessibility. This dimension refers to organization's provision for capturing the voice of the customer when the service failure occurs (Smith, et al., 2009). Organizations that are high in accessibility make it easy for their customers to report complaints. A multichannel approach is the most effective way to guarantee accessibility; along traditional channels (e.g. toll-free telephone numbers, e-mail addresses, feedback cards; Hart, Heskett, \& Sasser, 1990; Tax \& Brown 1998), online social media like Twitter or Facebook are becoming relevant complaint channels (Larivière, et al., 2013).

Formality. Formality refers to the degree that a recovery system is driven by explicit rules, procedures, and norms (Smith, et al., 2009). The basic idea is that any system requires a certain degree of formal documentation, such that every actor within the system knows what is required and allowed. Homburg and Fürst (2005) suggest that organizations need to develop three types of recovery guidelines: Process, behavioral, and outcome guidelines. Process guidelines set the rules on how frontline employees register and forward complaints, and whether time standards exist for handling complaints and informing customers. Behavioral guidelines are set to provide frontline employees with directions on how to interact with complaining customers, such as apologizing, being polite, showing empathy, and taking responsibility. Outcome guidelines are organizational policies that organizations set for compensating complainers and might include instructions on replacing the goods, reperforming the service, and providing delayed (vouchers or store credit) or immediate (discounts or money back) monetary compensation (Roschk \& Gelbrich, 2014).

Decentralization. Decentralization is the locus of authority or devolution of responsibilities for handling the recovery activities (Smith, et al., 2009). In a recovery context, this concept is also described in terms of organizational empowerment, i.e. organizations' implementation of practices that distribute power, information, knowledge, and rewards throughout the organization (Bowen \& Lawler, 1992). As customers expect a quick resolution 
to their complaints (Gelbrich \& Roschk, 2011), allowing employees to make decisions themselves without asking for approval forms an integral part of a recovery system.

Comprehensiveness. Comprehensiveness is the degree to which organizations develop a good understanding of the range of solutions that are practical, possible, fair, and understood by customers (Smith, et al., 2009). The literature provides numerous insights into how organizations can respond to complaints. Davidow (2003) and Gelbrich and Roschk (2011) provide extensive overviews of recovery options. In ideal situations, organizations should set an exhaustive list of potential recovery options for different types of failures. For example, when deciding about appropriate levels of compensation (as defined by the outcome guidelines), management should consider the type of failure: A monetary failure should be recovered with an immediate monetary compensation, flawed goods should be recovered by replacing or fixing the goods, and flawed service should be compensated by replacing or reperforming the service (Roschk \& Gelbrich, 2014).

Human intensity. Human intensity embodies the set and the magnitude of resources committed to recovery in the form of employee training and evaluation (Smith, et al., 2009). Organizations are aware that frontline employees are key to service recovery. About one out of four satisfactory service encounters involves the frontline employees' favorable behavior during service recovery, whereas about one out of two unsatisfactory encounters involves the employee underperforming during service recovery (Bitner, Booms, \& Tetreault, 1990). Organizations thus need to develop human resource management practices for service recovery, such as providing training, implementing reward systems, and developing employee performance evaluations.

System intensity. System intensity refers to the degree to which an organization dedicates resources to the alteration and improvement of current operations (Smith, et al., 2009). It reflects the capacity to use failure and customer complaint data to identify the root cause of a 
failure and to correct those processes that caused failures (Haunschild \& Sullivan, 2002). Researchers indicate that, to use customer complaints for process improvements, organizations need to collect and store complaint information, analyze these complaints, assess the costs associated with improvements, and finally implement the improvement (Johnston \& Michel, 2008). Recently, the task of collecting and analyzing complaint information has been supported by data mining and text mining procedures (e.g. Chen, Shie, \& Yu, 2012; Villarroel Ordenes, Burton, Theodoulidis, Gruber, \& Zaki, 2014).

Influence. Influence reflects the degree to which customers are involved in the service recovery process and can control the handling of a service failure. This requires asking customers for input into how a service failure should be addressed, or altering the recovery process based on customer input (Smith, et al., 2009). Including customers in the process has a significant effect on perceptions of its effectiveness, especially if the level of customer participation in recovery matches with the level of co-creation during service delivery (Heidenreich, Wittkowski, Handrich, \& Falk, 2015).

\section{Outcomes of the Service Recovery System}

Despite Hart et al. (1990) calling service recovery a "profitable art" (p. 148), few studies have determined its impact on financial outcomes. Johnston's (2001) and Johnston and Michel's (2008) collected survey data collected among 40 and 60 managers of service organizations in the U.K., respectively. Their findings show that organizations with formal complaint management procedures perform better financially (as expressed by managerial perceptions of profitability, lifetime value, and costs) than organizations that lack formal procedures. This relationship occurs because of (i) higher levels of customer satisfaction and retention, (ii) higher levels of employee attitudes and retention, and (iii) more efficiency. In their analysis of 151 Spanish firms, Santos-Vijande, Diaz Martin, Suarez-Alvarez and Belén del Rio-Lanza (2013) show that organizations with a strong service recovery system have a 
better business performance (as measured by sales and market share, among others). This relationship, however, is mediated by employee outcomes (e.g. satisfaction, retention, and absenteeism) and customer outcomes (e.g. satisfaction, loyalty, perceived value, and perceived brand image).

In their survey of 158 organizations, Smith and Karwan (2010) identify three different organizational profiles: Recoverers (i.e. organizations that strongly focus on all important characteristics of a service recovery system; $39.2 \%$ of the organizations), followers (i.e. organizations that focus on all characteristics, but not with the same intensity as recoverers; $42.4 \%$ of the organizations) and laggards (i.e. organizations with a suboptimal focus on the service recovery system; $18.4 \%$ of the organizations). These profiles differ markedly among them, with recoverers scoring higher than followers and laggards on managerial perceptions of capability improvement, customer satisfaction and market performance.

Tax and Brown (1998) also discuss the outcomes resulting from complaint-based process improvements. The authors suggest that, while handling a complaint generates customer loyalty among a single complaining customer, using complaints for process improvements contributes to current and future customers' satisfaction over many encounters. In addition, complaint-based process improvements contribute to collective employee satisfaction and loyalty by decreasing the need of dealing repeatedly with complaining customers on the same failure. These collective employee and customer outcomes, in turn, affect firm performance. Other studies focus on the financial costs and outcomes associated with customer recovery. Sim Song and Killough (2010) show that, in the airline industry, service recovery efforts (reducing mishandled baggage and complaints) are associated with short term and long term financial performance as measured by return on sales. Knox and Van Oest (2014) also provide simulations of the costs and benefits associated with recovery for different recovery scenarios, and show that the financial benefits of handling customer complaints outweighs the costs. 
These studies report interesting findings, but should be interpret cautiously as they rely on managerial perceptions of business performance, and not on multi-source data. To date, only two studies employ such data. Homburg and Fürst (2005) collected survey data among managers $(n=110)$ and customers $(n=550)$ of 110 German firms, and aggregated the customer data at the firm level. Their analysis shows that organizations who develop formal guidelines for complaint handling (i.e. the formality dimension of the service recovery system) and create a support for the employees handling complaints (i.e. the human intensity dimension) obtain higher levels of customer perceived justice, satisfaction, and loyalty. De Jong and De Ruyter (2004) collected survey data among managers $(n=61)$, employees $(n=$ 809) and customers $(n=1,724)$ nested within the branches of a Dutch bank, and aggregated the employee and customer data at the branch level. Their analysis shows that branches who develop complaint management procedures (i.e. formality and comprehensiveness dimension), empower their frontline employees (i.e. decentralization), and create a supportive environment (i.e. human intensity) have employees who perform better during service recovery, which in turn enhances customer satisfaction, loyalty, and customer usage rates of the services offered.

Thus, at the macro level, research suggests that a well-designed service recovery system allows organizations to attain performance through internally-focused outcomes such as operational efficiency and employee recovery performance, and externally-focused outcomes such as customer outcomes. Yet to date, the majority of our knowledge on the firm-level relationships between a service recovery system and firm performance is based upon studies with relatively limited sample sizes in which managerial perceptions predominate over objective data. There is a clear need for more studies using multi-source data to better understand the macro-level relationships surrounding service recovery.

\section{Micro-level relationships}


In the service recovery literature, micro-level studies aim at capturing individual-level phenomena that occur in interpersonal and intrapersonal processes. Two theoretical phenomena are investigated at this level. The first has developed in the human resource management literature and deals with employee recovery performance, its antecedents and consequences. The second has developed in the marketing discipline and concerns customer satisfaction with recovery, its drivers and outcomes. In the following sections, we provide a more in-depth discussion of the research examining these issues.

\section{Antecedents and Consequences of Frontline Employees' Recovery Performance}

At an individual employee level, most research examined employee's recovery performance, and its antecedents. Early research defines service recovery performance as the effectiveness of employees in satisfying complaining customers (Boshoff \& Allen, 2000), and as frontline employees' perceptions of their own abilities and actions to resolve service failures (Babakus, Yavas, Karatepe, \& Avci, 2003). Later work considered service recovery performance as the behaviors in which frontline employees engage to recover complaining customer: Making an apology, solving the problem, being courteous, providing an explanation, and handling the complaint promptly (Liao, 2007).

The antecedents of frontline employees' recovery performance have been examined through several theoretical lenses that provide valuable frameworks to the study of the different features of recovery performance, but that make a classification of the various antecedents difficult ${ }^{1}$. We therefore root our synthesis in the Job Demands-Resources model (JDR), which is a comprehensive job design model (Bakker \& Demerouti, 2007). The JDR assumes that employees' functioning is influenced by a variety of job characteristics that can

\footnotetext{
${ }^{1}$ Major theories employed to identify the antecedents of employees' recovery performance include attitude theory (e.g. Babakus et al., 2003), stressor-strain-outcome theory (e.g. Choi, Kim, Lee, \& Lee, 2014), role theory (e.g. Ashill \& Rod, 2011), or conservation of resources theory (Ashill, Rod, Thirkell, \& Carruthers, 2009).
} 
be categorized into job demands (i.e., job aspects that require sustained effort and are therefore associated with physiological or psychological costs) and job resources (i.e., job aspects that are functional in achieving work goals and stimulate personal growth and learning). Job demands and job resources affect performance through the mediating processes of job burnout and job engagement (Bakker \& Demerouti, 2007). Job burnout involves frontline employees' emotional exhaustion (i.e., the lack of energy and a feeling that one's emotional resources are expended; Ashill \& Rod, 2011) and depersonalization (i.e., the uncaring attitudes towards customers and a detachment from work; Ashill \& Rod, 2011). Typical job engagement variables examined in the service recovery literature involve job satisfaction (i.e., a person's positive emotional state resulting from an appraisal of his or her job experiences; Babakus, et al., 2003), organizational commitment (i.e., the strength of an employee's psychological bond and level of psychological investment in the employing organization; Babakus, et al., 2003), vigor (i.e., the levels of energy and mental resilience while working and the willingness to invest effort in one's work, Bakker \& Demerouti, 2007), dedication (i.e., the level of involvement in one's work and experiencing a sense of significance, enthusiasm, inspiration, pride, and challenge; Bakker \& Demerouti, 2007), and absorption (i.e., the level of concentration and happy engrossment in one's work; Bakker \& Demerouti, 2007).

Interestingly, recent developments in the JDR model indicate that burnout and work engagement are not only determined by environmental factors such as job demands and job resources, but may also be influenced by individual characteristics, coined as personal resources. Personal resources are highly valued aspects, relating to resilience and contributing to individuals' potential to successfully control and influence the environment. They might relate to burnout and work engagement directly, or function as a buffer for job demands (Van den Broeck, Van Ruysseveldt, Vanbelle, \& De Witte, 2013). Against this backdrop, we 
classify the various antecedents of frontline employees' recovery performance as either job demands, job resources, personal resources, job burnout, or job engagement ${ }^{2}$. We discuss these variables' main relationships with recovery performance next.

Job demands. Typical job demands examined in the service recovery literature are role stressors and customer-related social stressors. The former include role ambiguity (i.e., employee's confusion about the expectations of what his/her responsibilities are), role conflict (i.e., the difference an employee perceives between job expectations as communicated by multiple sources), and role overload (i.e., an inappropriate magnitude of requirements or workload; Ashill \& Rod, 2011). The latter concern the relationship with demanding and even aggressive customers. Among studies that have examined customer-related social stressors (Dormann \& Zapf, 2004), customers' intentions to harm frontline employees is the most investigated (Choi, Kim, Lee \& Lee, 2014). Other customer-related social stressors, such as disproportionate customer expectations, ambiguous customer expectations, and hostile, unpleasant customers have received far less research attention (Choi, et al., 2014). Overall, employees experiencing job demands are more likely to have feelings of burnout and lower job engagement (Crawford, LePine, \& Rich, 2010), although research reports mixed findings. For example, while role ambiguity has mostly a negative effect on recovery performance, some research reports significant (e.g. Rod, Ashill, \& Carruthers, 2008) and non-significant effects (e.g. Karatepe, 2006) of role overload on employee recovery performance. In a similar vein, researchers report no (e.g. Karatepe, 2006) or even positive (e.g. Karatepe \& Sokmen, 2006) effects of role conflict on recovery performance. The effects of job demands on recovery performance are in need of further exploration.

\footnotetext{
${ }^{2}$ We asked three professors in Organizational Behavior, familiar with the JDR, to assign the various antecedents reported in literature to one of these five categories. The intercoder reliability, as measured by Krippendorfer's alpha, was satisfactory $(91,47 \%)$. Any differences were resolved through discussion.
} 
Job resources. The literature proposes several job resources. Empowerment, training, rewards, and customer service orientation are the most investigated. Empowerment refers to frontline employees' feeling of authority and autonomy to handle customer complaints (Babakus, et al., 2003), and training refers to an employees' appraisal of receiving education, for example to learn how to handle dissatisfied customers (Babakus, et al., 2003). Rewards concern employees' appraisal of the financial and non-financial rewards for handling complaints well (Babakus, et al., 2003). Customer service orientation, finally, describes employees' perceptions of the organizational culture of the service provider for customer service. Smith, Fox, and Ramirez (2010) show that employees' perceived investments by the organization in a recovery system affect their individual perception of the recovery climate, as these investments signal that the organization is taking complaining customers seriously. Employees high in job resources are generally less likely to experience burnout, and are more engaged. These feelings ultimately benefit their performance (Babakus, et al., 2003; Rod \& Ashill, 2009).

Personal resources. Employees' recovery performance also depends on their own resources. In particular, prior research suggests that employees' customer orientation (i.e., employee's tendency to meet customer needs in an on-the-job context; Choi, et al., 2014), emotional intelligence (i.e., an employee's ability to monitor and discriminate among one's own and others' feelings, and use this information to guide one's behavior; Lee, Kim, \& Aeeun, 2013) and trait competitiveness (i.e., an employee's enjoyment of interpersonal competition and the desire to win and to be better than others; Karatepe, 2006) decrease job burnout (Choi, et al., 2014) and increase job engagement (Lee, et al., 2013), thereby enhancing employees' recovery performance. Interestingly, personal resources seem to moderate the relationships of job demands with recovery performance. For example, Choi et al. (2014) show that customer orientation weakens the impact of customer-related social 
stressors on recovery performance. However, the literature seems to have paid little attention to the effects of personal resources on employees' recovery performance to date.

Outcomes of recovery performance. Research shows that employees who feel that they perform well during service recovery display lower intentions to resign (e.g. Boshoff \& Allen, 2000). Employees' intentions to resign are deemed highly undesirable because they lead to a reduction of productivity, and a gradual emotional detachment from the organization (Boshoff \& Allen, 2000). Moreover, employees’ recovery performance increases customer outcomes. Tax and Brown (1998) therefore suggest that "developing hiring criteria and training programs that take into account employees' service recovery role directly affects customers' fairness evaluations.” (p. 81). Analyzing 320 dyadic employee-customer interactions, Maxham and Netemeyer (2003) indeed show that employee evaluations of the organizational complaint handling procedures result in higher customer ratings of employee performance, which, in turn, increases customer justice perceptions. We discuss the role of customer justice perceptions next.

\section{Drivers and outcomes of customer satisfaction with recovery}

Researchers agree that justice is a key component in recovery evaluations at the customer level of analysis (Michel, et al., 2009). Justice refers to the degree to which customers feel they have been treated fairly following a service failure (Smith, et al., 1999). The literature distinguishes between distributive justice, procedural justice, and interactional justice (Gelbrich \& Roschk, 2011; Orsingher, et al., 2010). Distributive justice refers to the perceived fairness of the benefit customers receive to offset the dissatisfaction caused by the service failure (Tax \& Brown, 1998). Benefits include monetary or psychological compensations such as replacing products or providing an apology (Gelbrich \& Roschk, 2011). Interactional justice refers to how customers perceive the way they are treated (Tax \& Brown, 1998), which is driven by favorable employee behavior such as providing explanations or being friendly 
(Gelbrich \& Roschk, 2011). Finally, procedural justice refers to customers' perceptions of the provider's decision-making process (Tax \& Brown, 1998). Procedural justice is mainly driven by procedures such as a speedy recoveries or flexible solutions (Gelbrich \& Roschk, 2011).

The effects of perceived justice on customer outcomes were summarized in two metaanalyses. Orsingher et al. (2010) analyze 50 studies dedicated to service recovery; Gelbrich and Roschk (2011) analyze 87 studies examining the role of perceived justice in service recovery. Both meta-analyses examine the effects of the three justice dimensions on customer satisfaction with service recovery, which refers to the customer's evaluation of how well a organization has handled a customer complaint (Orsingher, et al., 2010). Distributive justice generally has the strongest influence on customer satisfaction with service recovery, whereas the effects of interactional justice and procedural justice are less pronounced (Gelbrich \& Roschk, 2011; Orsingher, et al., 2010). Yet all dimensions are relevant to consumers, suggesting that the service recovery system and/or the frontline employee should be aware that complainers evaluate the organization's recovery efforts in terms of what is provided to the them (distributive justice), how it is provided (interactional justice), and why that particular response is provided (procedural justice).

Individual customers' satisfaction with customer recovery influences a variety of outcome variables; overall satisfaction, repurchase intentions, and word-of-mouth intentions being amongst the most frequent. Overall satisfaction represents the global judgment of a service provider across multiple service encounters (Jones \& Suh, 2000). Repurchase or loyalty intentions are a customer's intention to do business with a service provider in the future (Gelbrich \& Roschk, 2011), which predict customer retention (Larivière, 2008). Finally, word-of-mouth intentions refer to the likelihood of spreading positive information on a service provider to other people (Gelbrich \& Roschk, 2011). Word of mouth is important after consuming a product or service, as it provides face-to-face information that is highly 
credible and might lead to new customer acquisitions. The relationships among these variables in a service recovery context are not clear-cut. Customer satisfaction with service recovery has no effect on overall satisfaction. The justice dimensions thus directly impact overall satisfaction, with interactional justice exerting the strongest influence. Both Orsingher et al. (2010) and Gelbrich and Roschk (2011) suggest that distributive justice creates customer satisfaction with the recovery, yet the way in which the complaint is handled mainly determines customers' overall satisfaction. Satisfaction with service recovery and overall satisfaction both influence behavioral intentions.

Effects of service recovery on customer behavior. Of all the papers we retrieved, only three examine actual customer behavior following recovery. Larivière and Van den Poel (2005) observed 2,326 complaining customers over a three-year period, and randomly sampled another 2,500 noncomplaining customers from the financial service organization's database. The authors examine new product adoption in the (at least) 12 months following the complaint, among three customer groups: (i) Customers who complained, and received a satisfactory recovery, (ii) customers who complained, and received an unsatisfactory recovery, and (iii) non-complaining customers. Interestingly, their results show that complaining customers are the most loyal customer segment, as both complaining customers who received either a satisfactory or an unsatisfactory recovery purchased a new product faster than the control group of noncomplaining customers. Evanschitzky, Brock, and Blut (2011) conducted telephone interviews with 9,461 customers of a fast food delivery service provider; 388 customers reported a failure, of which 233 customers complained to the organization. The authors also tracked the complaining customers' purchase volume in the six months following the complaint. Their results show that satisfaction with customer recovery positively affects purchase volume, yet this relationship becomes less strong when customers' 
level of affective commitment toward the organization increases. Both studies thus suggest that loyal customers tend to be less sensitive toward the service provider's recovery actions.

Finally, Knox and Van Oest (2014) observed 20,000 customers over a 2.5 year period, during which 805 customers voiced a total of 933 complaints. Their results show that complaints increase customer churn (i.e. the probability that a customer stops buying), but also that a successful recovery can offset the loss associated with a complaint. The paucity of research analyzing customer behavior is in marked contrast with the abundance of research using customer perceptual metrics. Although behavioral measures from complaining customers are often difficult to obtain, more effort is needed from researchers to obtain data on complainants' actual behavior.

\section{Multilevel Relationships}

So far, our synthesis has focused on relationships that occur either at the firm level or the individual employee or customer level. Although these studies are insightful, they face a common limitation in that they frequently use data from a single level to infer relationships that occur at multiple levels (Wong, 2016). Service recovery actions and outcomes require an understanding of the influences emanating at different levels of analysis. Bowen and Johnston (1999), for example, note that employees working for organizations that do not offer their frontline employees with the necessary tools and resources to deliver an effective service recovery to customers perform less during service recovery. Hultén (2012) suggests that the formality of organizations' service recovery policies affects how individual employees handle customer complaints in everyday practice. Therefore, a more thorough consideration of how service phenomena traverse multiple echelons of the organization is needed.

Multilevel research involves research that addresses how phenomena that occur at the firm level (i.e. parts of the service recovery system) affect perceptions that exist at the individual employee (e.g. empowerment) and/or customer (e.g. customer satisfaction) level. 
Whereas studies linking employees' and customers' individual -level constructs are starting to appear in recovery studies (Chan \& Wan, 2012; Maxham \& Netemeyer, 2003), there is a dearth of research modeling macro-level predictors and assessing their effects on employee and/or customer outcomes. Surprisingly, only two studies report the results of a multilevel examination of service recovery issues.

De Jong and De Ruyter (2004) examine frontline employees' adaptive (i.e. employees ability to adjust their behavior to properly manage complaints) and proactive (i.e. employees behavioral initiatives to change existing practices to prevent future complaints) recovery performance at an individual and branch level. They collected data among 809 frontline employees working in 61 branches, and find that four behavior-shaping factors (empowerment, customer complaint management, inter-team support and intra-team support) at the individual and at the branch level are significant antecedents of employees' recovery performance. Their research suggests that service recovery represents a collective responsibility and that standards of recovery behavior that are developed within the context of the branch also govern the behavior of the individual members.

Homburg, Fürst and Koschate (2010) conducted a multilevel analysis of 110 firms and 634 customers to show that organizations' quality of complaint handling design, which refers mainly to the formality dimension of the service recovery system, affects customers' perceived justice of complaint handling. This relationship however is contingent upon problem-related (i.e. failure severity, perceived product importance, and attribution of responsibility to the organization), relationship-related (i.e. intensity of business relationship), psychographic (i.e. appreciation of product quality), and sociodemographic (i.e. age, gender) customer characteristics.

These two studies offer initial insights into multilevel relationships associated with service recovery. In particular, the results show that investments in a service recovery system 
affect individual employees' and customers' outcomes. Given that service recovery involves relationships that are nested at different levels of the organization, the limited number of studies taking a multilevel approach is problematic and calls for more research.

\section{Microfoundations}

The previous section mainly discussed research on 'downward' multilevel effects, in the sense that constructs located at Level 2 (and Level 1) are expected to affect a construct situated at Level 1. Research examining microfoundations typically focuses on how constructs located at Level 1 (and Level 2) affects a construct situated at Level 2. Microfoundations researchers examine how individuals and their interactions influence macro-level outcomes. Understanding microfoundations is deemed important, as they form "a critical causal link in the business and management process chain" (Devinney, 2013, p. 83).

Typical microfoundations occurring in service management literature are the link between individual employee outcomes and collective employee outcomes. For example, collective employee outcomes are likely to emerge due to a similar work environment and due to similar employee dispositions that result from the attraction - selection - attrition process within an organization (Schneider, 1987). Microfoundations research is virtually absent in service recovery. Only few studies advanced how collective phenomena emerge from individual-level phenomena. De Jong and De Ruyter's (2004) findings suggest that the strong within-branch agreement concerning employees' recovery performance is likely to emerge from every individual employee's recovery performance. It is reasonable to think that customers obtaining service recovery from organizations with established recovery systems receive a similar service recovery. After all, the service recovery system sets out the different channels through which a customer can complain (i.e. accessibility), develops guidelines on how employees should deal with complaining customers (i.e. formality), and offers the frontline employees an overview of recovery options that work in a given situation (i.e. 
comprehensiveness), among others. As a result, different individual customers complaining to an organization with a strong service recovery system are all likely to be satisfied with the organizations' recovery efforts. Homburg and Fürst's (2005) thus found a strong within-firm agreement concerning customers' perceived justice, satisfaction with complaining handling, and loyalty. Thus, collective customer outcomes emerge from individual customer outcomes.

Employees dealing with customer complaints can also contribute to firm-level process improvements. Van der Heijden, Schepers, Nijssen, and Ordanini (2013) show that employees routinely evaluate their recovery performances, and improve the service recovery system accordingly. Qualitative research in the health care industry indicates that employees in control of processes that cause failures might help organizations turning these incidents in organizational learning opportunities. More precisely, employee first problem-solving behavior can preclude improvement by obscuring the existence of problems and preventing operational and structural changes that would avoid the same failures from happening again. Second-order problem solving (i.e. communicating to the person responsible for the problem; bringing it to managers' attention; sharing ideas about what caused the problem and how to prevent recurrence; implementing changes) contributes to lasting improvements (Tucker, 2004, Tucker \& Edmondson, 2003).

Just as with multilevel research, the literature is in strong need of microfoundations research. The literature provides only initial insights into the role of employees in implementing complaint-based process improvements, but an in-depth exploration of this issue is currently lacking in literature. In a similar vein, research reports indicate that complaining customers are potentially a rich source of information for organizations: the U.K. National Complaints Culture Survey (2006) indicates that people complain not only to get their own problem solved, but also to fix the problem for others. Understanding how 
individual customers can contribute to process improvements, however, has not been examined in current service recovery research.

\section{Future Research Agenda}

The overall aim of this paper was to develop a unified view on service recovery. This endeavor allows us to formulate several future research opportunities at the macro-level, the micro-level, and across levels.

\section{Future research opportunities at the macro level}

Despite some noteworthy contributions (Smith, et al., 2009, 2010; Santos-Vijande, et al., 2013), the literature on service recovery systems, its antecedents, and its outcomes is still in its infancy. Therefore, there is a need for more research on validating the research on service recovery systems, identifying antecedents to service recovery systems, and understanding outcomes of the service recovery system.

Validating and conceptualizing the service recovery system. The current sevendimensional conceptualization of a service recovery system is mainly based on one dataset (Smith, et al., 2009), and has not been replicated to date. Given the importance of replication studies in science, future research is necessary to validate the current service recovery system scale. In addition, future research should examine the relative importance of the various dimensions in a service recovery system. Parasuraman (2006), for example, indicates that research should disclose whether organizations should invest in delivering reliable service to prevent problems (i.e. system intensity) or in providing customers superior recovery when problems occur (i.e. comprehensiveness and formality) in order to increase firm performance.

More work is needed on the conceptualization of a service recovery system. Current conceptualizations of the service recovery system are rather reactive in nature. For example, accessibility is found to be an important dimension of a service recovery system, so customers can easily voice their complaints to the organization (Smith, et al. 2009). Modern technology, 
however, allows organizations to detect service failures before these are noticed by customers. For example, Deutsche Post DHL, an international logistics and delivery firm, implemented a tracking system which allows the organization to detect and rectify service failures (e.g. replacing the product) before the package is delivered to the customer. In addition, social media make it easier for organizations to proactively detect customer complaints that are not necessarily directed to the organization itself (Larivière, et al., 2013). Future research might examine how approaching service recovery from a proactive perspective influences the current relationships proposed in our framework.

Identifying antecedents of service recovery systems. There is a paucity of research on the antecedents of service recovery systems; future research thus might examine why organizations develop service recovery systems in the first place. Smith and Karwan (2010) show that organizations with strong service recovery systems are typically larger, work as franchises, or are organized into branches. The literature is in need of examining antecedents that are related to macro theories developed in strategy. For example, to date is unclear whether organizations develop service recovery systems because of an instrumental motivation (the perception that investing in recovery likely leads to increased competitiveness) or because of a normative motivation (a sense of responsibility or duty; Bansal \& Roth 2000), and whether this different approach produces different outcomes.

Understanding the outcomes of a service recovery system. The current studies provide useful insights into the service recovery - firm performance relationships, yet these studies either focus on the costs and benefits associated with a particular type of service recovery or rely on subjective managerial perceptions of firm performance. A robust and comprehensive examination of the link between investments in service recovery and firm performance using objective outcome measures (e.g. such as shareholder value as expressed by Tobin's Q, or Carhart's Four Factor Model; see Larivière, et al., 2016 for an example) is absolutely 
necessary. Such examination is particularly important since many organizations consider service recovery as a cost rather than an investment (Rosenbaum, 2015).

The underlying processes linking investments in service recovery to financial outcomes also deserve more attention. For example, an organization's intangible resources could mediate the service recovery system -firm performance relationships. Organizations like Zappos.com or Amazon have a strong reputation for service recovery, which should contribute to their brand equity (i.e. the value of the brand) and customer equity (i.e. the value of the customer base). Future research might examine this issue in more detail.

\section{Future research opportunities at the micro-level}

Even though the research at the micro-level is well-developed, several opportunities for future research exist. In particular, future research might enhance our understanding of (i) the antecedents of employees' recovery performance, and (ii) how customers evaluate an organization's service recovery efforts.

Antecedents of employees' recovery performance. There is a need for an increased understanding of factors influencing employee recovery performance. For example, the role of personal resources (e.g. customer orientation) is largely understudied. The current literature seems to suggest that frontline employees high in customer orientation perform better during service recovery (Choi, et al., 2014), yet future research is necessary to fully explore the role of personal resources. In line with the job demands-resources model, the in-depth examination of personal resources might also help clarifying the mixed findings concerning the relationship between job demands and recovery performance.

In addition, the theoretical lens of organizational justice could help investigating if employees' perceived justice of the organization's recovery system affects employee's recovery performance. Research in organizational behavior has shown that employees' perception of procedural justice affects task performance and job dedication (Cropanzano, 
Bowen, \& Gilliland, 2007). An examination of how employees' evaluation of the fairness of the recovery system affects their recovery performance and, in turn, customer perceived justice would provide a better understanding of the mutual relationship between employees and customers.

Customer service recovery evaluations. Justice theory has been the theoretical underpinning of many studies examining customer reactions to service recovery. However, justice perceptions explain only between $43 \%$ and $63 \%$ of the variance in satisfaction and behavioral intentions measures (Gelbrich \& Roschk, 2011). Future research thus might examine additional mediators of the relationships between recovery actions and customer satisfaction with recovery. For example, Van Vaerenbergh, Larivière and Vermeir (2012) show that customer reactions to explanations about complaint-based process improvements are mediated by both perceived justice and perceived relationship investment. Combining these different theoretical frameworks (i.e. justice theory and reciprocity theory) might provide a more comprehensive understanding of the processes underlying service recovery's effects on individual customers.

Finally, most studies in the service recovery literature focus on customer satisfaction and behavioral intentions as dependent variables. The literature is in strong need of studies examining actual customer behavior, such as share-of-wallet, customer lifetime value, or individual customer profitability. In this context, the two studies examining actual customer behavior show that loyal customers are more inert toward a service provider's customer recovery. Future research might examine the underlying process of this inertia, and examine whether this inertia still exists when considering other behavioral metrics.

\section{Multilevel future research opportunities}

Even though service recovery research is multilevel by its very nature, the very limited number of studies taking a multilevel approach is of major concern. In service organizations 
employees are typically nested within higher collectives such as branches and teams, which are nested in turn within organizations and industries. Such interdependence must be considered theoretically and analytically, but is not reflected in contemporary thinking about service recovery. Researchers might benefit from adopting a multilevel approach to their research designs, data collection, and data analysis. Fully exploring the potential of multilevel studies still represents one of the major areas for improvement in service management research (Subramony \& Pugh, 2015), and even more in service recovery. Multilevel research is necessary in three main areas. The literature is in need of understanding how the service recovery system affects individual frontline employees, how organizational process improvements affect individual employees and customers, and how supervisors' leadership behaviors drive employee recovery performance and customer outcomes.

The effect of service recovery systems on frontline employees. Given that customer perceptions of service recovery are driven by both the service recovery system (i.e. the technical system) and individual frontline employees behavior (i.e. the social system), sociotechnical systems theory (STS) might offer a fruitful starting point for examining multilevel effects in service recovery. STS is typically a multilevel theory, as it bridges the phenomena that occur at the firm level with those that occur at the employee level (Kozlowski \& Klein, 2000). STS recommends organizations to align their technical system (tools, techniques and knowledge) with the social system (employees' attitudes and beliefs; Pasmore \& William, 1978). Some authors (Smith, et al., 2010) postulate that the technical part of the service recovery system creates a social system, allowing employees to deliver satisfactory recovery, and that organizations need a mechanistic (i.e. install clear guidelines) and an organic approach (i.e. create a favorable internal environment among employees) to resolve customer complaints well (Homburg \& Fürst, 2005). 
Understanding the balance between investing in a technical system on the one hand, and developing a social system on the other hand, provides ample opportunities for future research. For example, the service recovery system might affect employee job demands, but the sign of the relationship might depend on the type of structural dimension. Formality (clear guidelines) and comprehensiveness (detailing fair and feasible solutions) might reduce role ambiguity and role overload as they should make it easier for employees to find appropriate responses to complaints. On the other hand, influence (involving customers into the process) could increase role ambiguity and role overload if customers demand solutions not contemplated in the formal guidelines, or if responsibilities are not decentralized to employees (Chan \& Lam, 2011).

In a similar vein, service recovery system actions taken at the firm level might affect customer-related social stressors. Employees can be the target of verbal aggression because customers get angry at organizations that do not invest sufficiently in a recovery system that can rectify problems. For example, Surachartkumtonkun, Patterson and McColl-Kennedy, (2013) reported violent behavior from customers who experienced an excessively long wait in a call center line. Due to their boundary-spanning role, employees are likely to be permeable to customer reactions. These findings indicate that the technical and social system should be in balance, yet researchers have not yet explored this topic in detail.

The aforementioned issues also suggest the need to enrich the accuracy of the representation of the dimensions of the service recovery system by collecting measures from multiple informants and not from a single respondents (Smith, et al., 2009). To gain a comprehensive picture of the dimensions of the recovery system, of its implementation and its impact on recovery performance researchers need to conceptualize and measure it in a variety of organizations at the managerial, team, and employee level of analysis.

The impact of process improvements on employees and customers. A good service recovery system also requires organizations to improve those processes that caused failures to 
occur. Such process improvements affect collective employee attitudes and customer outcomes (Johnston, 2001; Tax \& Brown, 1998), yet little is known about how organizational improvements affect individual employees and customers. A rich literature examines how employees react to organizational change, showing - among others - that employees might form different attributions about changes in the organization's processes, policies, or procedures. These attributions, in turn, affect the impact of the process improvements on employees' satisfaction, commitment, and motivation (Reichers, Wanous, \& Austin, 1997). If an organization implements complaint-based process improvements, employees might attribute these improvements either to complaining customers (if such information is provided) or to managerial action (if no such information is provided). Future research might therefore examine whether employees accept complaint-driven process improvements (e.g. new rules, policies, and values) more easily than managerial-driven improvements.

Future research might also examine customer reactions to complaint-based process improvements. As some changes in service delivery may imply a loss of value (e.g. a focal provider no longer taking credit card information over the phone because of complaints about safety), future research could explore customer reactions to these changes. Researchers might take a longitudinal approach to examining these issues, by tracking individual-level employee and customer perceptions before and after the implementation of the process improvements across a variety of organizations.

The role of supervisors in service recovery. Despite the extensive focus on leadership behavior in management research (Yukl, 2012), none of the reviewed studies examined how a supervisor's leadership behavior affects frontline employees' recovery performance. As typical leadership behaviors involve empowering, supporting, and developing employees, next to engaging in problem-solving and clarifying explicit policies and standard procedures, among others, (Yukl, 2012), the supervisor's leadership behavior might affect frontline 
employees' recovery performance. Researchers can also examine how managers in service organizations can create work environments supportive of service recovery.

On the other hand, Salvaggio, et al. (2007) note that customers often ask to speak to supervisors when service failures occur. Customers do so as they believe that supervisors play a pivotal role in making things better. To date, it is unclear to what extent supervisors taking control over the customer complaint affects frontline employees' job demands and job resources. Future research might therefore examine the effect of supervisors resolving the complaint themselves (versus redirecting the complaining customer to the frontline employee) on frontline employees' job attitudes.

\section{Future research opportunities on microfoundations}

Subramony and Pugh (2015) highlight the lack of studies regarding the role of individuallevel constructs and actors in shaping higher-order relationships. Service recovery research suffers from the same problem. Various macro-level variables in Figure 1 are actually expected to emerge from individual-level phenomena. Collective employee attitudes are expected to emerge from individual employee attitudes, especially since frontline employees share perceptions of their work environment with each other and perform similar tasks (Subramony \& Pugh, 2015). Collective customer outcomes are likely to occur since customers are served by frontline employees who are supported by similar systems. Important to note, however, is that collective customer outcomes and individual customer outcomes should not be considered as interchangeable: A recent study combining firm-level customer satisfaction (Level 2) and individual customer satisfaction (Level 1) data to predict shareholder value (Level 2), shows that only relying on aggregated customer satisfaction data leads to an overestimation of this relationship. As a result, managers cannot rely solely on collective customer outcomes to take decisions that affect the individual level (Larivière, et 
al., 2016). These findings demonstrate the importance of examining microfoundations of phenomena emerging at the macro level.

In particular, the literature currently lacks an in-depth understanding of how individual actors (employees and customers) might contribute to process improvements at the firm level. Employee contributions to firm-level outcomes has been discussed in research linking HR practices to firm performance (Bowen \& Ostroff, 2004) through the lenses of multilevel relationships among HRM practices, individual employee attitudes, and firm performance. A similar microfoundations perspective linking the recovery system, employee-customer interactions at the individual level, and process improvements at the firm level could help understanding the mechanism through which a organization's investments in the recovery system translates in process improvements through the contribution of employees' and customers' skills and knowledge.

Future research might not only examine how employees and customers contribute to organization-wide process improvements, but also how individual employees and customers might contribute to changes in the recovery system itself (Van der Heijden, et al., 2013). For example, research recommends co-creating service recovery outcomes with customers (Heidenrich, et al., 2015). As a result, these co-created employee-customer interactions form a rich source of information about the recovery process itself. If customers often demand recoveries that fall outside the service recovery system's guidelines, these insights might be used to refine the recovery system.

Future research might adopt insights from knowledge management to better understand how organizations can extract service failure-related knowledge from employees and customers. For example, Anand, Glick, and Manz (2002) suggest that organizations need to develop absorptive capacity and foster social capital in order to benefit from knowledge vested in external parties. While Wirtz, Tambyah, and Mattila (2010) examine the role of 
social capital in driving employees' intentions to report customer feedback, the service recovery literature does not offer insights into how customer feedback from individual customers and collected by individual employees can be turned into process improvements.

\section{Examining cross-level interactions}

One particular benefit of taking a multilevel approach to understanding service recovery is the ability to examine cross-level interactions. To date, only Homburg, et al. (2010) show that contingency factors such as customer-perceived failure severity, or attribution of responsibility to the organizations, among others, moderate the relationship between organizations' quality of complaint handling guidelines (i.e. the formality dimension in the service recovery system) and customers' perceived justice. Hence, there is a large opportunity for researchers to contribute to our current body of knowledge by adopting a similar perspective. For example, contingency theory on sales interactions (Weitz, 1981) could be applied to examine whether frontline employees' personal resources (e.g. customer orientation) moderate the relationships between the service recovery system and customers' perceived justice. One can expect that an employee high in personal resources requires less resources from the service recovery system to handle customer complaints well, decreasing the strength of the aforementioned relationship. In a similar vein, future research might also examine to what extent employees' personal resources moderate the relationship between process improvements and individual employee outcomes. For example, employees high in customer orientation might be less resistant to change, if the process improvement was driven initially by customer complaints.

Research could examine to what extent supervisors' leadership behavior affects the relationship between the service recovery system and employees' recovery performance. For example, the relationship between the recovery system and recovery performance might be stronger when employees work with supervisors who emphasize employee empowerment (as 
it relates to decentralization), stimulate personal development (as it relates to human intensity), and help clarify organizational policies and procedures (as it relates to formality), among others (see Yukl, 2012). In terms of microfoundations, employees working with a supervisor who emphasizes not only organizational change and innovation (Yukl, 2012), but also considers service failure as a learning opportunity, might be more willing to contribute to complaint-based process improvements. Examining these questions can be quite challenging, as researchers need to collect data at different levels of the organization.

\section{Conclusion}

This paper offers a unified view of service recovery management, across disciplines and levels of theory and analysis. We organized this literature within an interdisciplinary framework to facilitate a better understanding of different disciplines examining service recovery, and provide guidelines on how organizations might set up service recovery procedures. It is our intention that this synthesis and integrative framework will assist researchers and managers to think differently about service recovery, and hope that the future research questions discussed in this article can enhance the research effectiveness of scholars interested in service recovery. 


\section{References}

Anand, V., Glick, W. H., \& Manz, C. C. (2002). Thriving on the knowledge of outsiders: Tapping organizational social capital. Academy of Management Executive, 16(1), 87-101.

Ashill, N. J., \& Rod, M. (2011). Burnout processes in non-clinical health service encounters. Journal of Business Research, 64(10), 1116-1127.

Ashill, N. J., Rod, M., Thirkell, P., \& Carruthers, J. (2009). Job Resourcefulness, Symptoms of Burnout, and Service Recovery Performance: An examination of call centre frontline employees. Journal of Services Marketing, 23(5), 338-350.

Babakus, E., Yavas, Y., Karatape, O. M., \& Avci, T. (2003). The effect of management commitment to service quality on employees' affective and performance outcomes. Journal of the Academy of Marketing Science, 31(3), 272-286.

Bakker, A. B., \& Deremouti, E. (2007). The job demands-resources model: State of the art. Journal of Managerial Psychology, 22(3), 309-328.

Bansal. P. \& Roth, K. (2000). Why Companies Go Green: A model of ecological responsiveness. Academy of Management Journal, 43(4), 717-736.

Bitner, M. J., Booms, B. H., \& Tetreault, M. S. (1990). The service encounter: Diagnosing favorable and unfavorable incidents. Journal of Marketing, 54(1), 71-84.

Boshoff, C., \& Allen, J. (2000). The influence of selected antecedents on frontline staff's perceptions of service recovery performance. International Journal of Service Industry Management, 11(1), 63-90.

Bowen, D. E., \& Johnston, R. (1999). Internal service recovery: Developing a new construct. International Journal of Service Industry Management, 10(2), 118-131.

Bowen, D. E., \& Lawler, E. E, III. (1992). The empowerment of service workers: What, why, how and when. Sloan Management Review, 33(3), 31-39. 
Bowen, D. E., \& Ostroff, C. (2004). Understanding HRM-firm performance linkages: The role of the 'strength' of the HRM system. Academy of Management Review, 29(2), 203221.

Broome, M. E. (1993). Integrative literature reviews for the development of concepts. In: Rodgers, B. L. \& Knafl, K. A. (Eds.), Concept Development in Nursing, Second edition, Philadelphia, PA: W.B. Saunders Co., 231-250.

Chan, K. W., \& Lam, W. (2011). The trade-off of servicing empowerment on employees' service performance: Examining the underlying motivation and workload mechanisms. Journal of the Academy of Marketing Science, 39(4), 609-628.

Chan, K. W., \& Wan, E. W. (2012). How can stressed employees deliver better customer service? The underlying self-regulation depletion mechanism. Journal of Marketing, 76(1), 119-137.

Chen, C. K., Shie, A. J., \& Yu, C. H. (2012). A customer-oriented organisational diagnostic model based on data mining of customer-complaint databases. Expert Systems with Applications, 39(1), 786-792.

Choi, C. H.; Kim, T.; Lee, G. \& Lee, S. K. (2014). Testing the stressor-strain-outcome model of customer related social stressors in predicting emotional exhaustion, customer orientation and service recovery performance. International Journal of Hospitality Management, 36(1), 272-285.

CMCC (2013). Will we ever learn? The sad state of customer care in America. Results from the 2013 customer rage study. Accessed at: http://www.customercaremc.com/wp/wpcontent/uploads/2014/01/KeyFindingsFrom2013NationalCustomerRageSurvey.pdf

Crawford, E. R., LePine, J. A., and Rich, B. L. (2010). Linking job demands and resources to employee engagement and burnout: A theoretical extension and meta-analysis. Journal of Applied Psychology, 95(5), 834-848. 
Cropanzano, R., Bowen, D. E., \& Gilliland, S. W. (2007). The management of organizational justice. Academy of Management Perspectives, 21(4), 34-48.

Davidow, M. (2003). Organizational responses to customer complaints: What works and what doesn't? Journal of Service Research, 5(3), 225-250.

De Jong, A., \& De Ruyter, K. (2004). Adaptive versus proactive behavior in service recovery: The role of self-managing teams. Decision Sciences, 35(3), 457-491.

Devinney, T. M. (2013). Is microfoundational thinking critical to management thought and practice? Academy of Management Perspectives, 27(2), 81-84.

Dormann, C., \& Zapf, D., (2004). Customer-related social stressors and burnout. Journal of Occupational Health Psychology, 9(1), 61-82.

Evanschitzky, H., Brock, C., \& Blut, M. (2011). Will you tolerate this? The impact of affective commitment on complaint intention and post-recovery behavior. Journal of Service Research, 14 (4), 410-425.

Gelbrich, K., \& Roschk, H. (2011). A meta-analysis of organizational complaint handling and customer responses. Journal of Service Research, 14(1), 24-43.

Grönroos, C. (1988). Service quality: The six criteria of good perceived service quality. Review of Business, 9(Winter), 10-13.

Hart, C. W. L., Heskett, J. L., \& Sasser, W. E. (1990). The profitable art of service recovery. Harvard Business Review, 68(4), 148-156.

Haunschild, P., \& Sullivan, B. I. (2002). Learning complexity: Effects of prior accidents and incidents on airlines' learning. Adminstrative Science Quarterly, 47(4), 609-643.

Heidenreich, S., Wittkowski, K., Handrich, M., \& Falk, T. (2015). The dark side of customer co-creation: exploring the consequences of failed co-created services. Journal of the Academy of Marketing Science, 43(3), 279-296. 
Homburg, C. \& Fürst, A. (2005). How organizational complaint handling drives customer loyalty: An analysis of the mechanistic and organic approach. Journal of Marketing, 69(3), 95-114.

Homburg, C., Fürst, A. \& Koschate, N. (2010). On the importance of complaint-handling design: A multi-level analysis of the impact in specific complaint situations. Journal of the Academy of Marketing Science, 38(3), 265-287.

Hultén, P. (2012). A Lindblomian perspective on customer complaint management policies. Journal of Business Research, 65(6), 788-793.

Jeffrey, P. (2003). Smoothing the waters: Observations on the process of cross-disciplinary research collaboration. Social Studies of Science, 33(4), 539-562.

Johnston, R. (2001). Linking complaint management to profit. International Journal of Service Industry Management, 12(1), 60-69

Johnston, R. \& Michel, S. (2008). Three outcomes of service recovery: Customer recovery, process recovery and employee recovery. International Journal of Operations and Production Management, 28(1), 79-99.

Jones, M. A. \& Suh, J. (2000). Transaction-specific satisfaction and overall satisfaction: An empirical analysis. Journal of Services Marketing, 14(2), 147-157.

Karatepe, O. M. (2006). The effects of selected antecedents on the service recovery performance of frontline employees. Service Industries Journal, 26(1), 39-57.

Karatepe, O. M. \& Sokmen, A. (2006). The effects of work role and family role variables on psychological and behavioral outcomes of frontline employees. Tourism Management, 27(2), 255-268.

Kendall, C. L. \& Russ, F. A. (1975). Warranty and complaint policies: An opportunity for marketing management. Journal of Marketing, 39(2), 36-43. 
Knox, G. \& van Oest, R. (2014). Customer complaints and recovery effectiveness: A customer base approach. Journal of Marketing, 78(5), 42-57.

Kozlowski, S. W. J. \& Klein, K. J. (2000). A multilevel approach to theory and research in organizations: Contextual, temporal, and emergent processes. In: Klein, K. J. \& Kozlowski, S. W. J. (Eds.), Multilevel Theory, Research, and Methods in Organizations: Foundations, Extensions, and New Directions. San Francisco, Jossey-Bass.

Larivière, B. (2008). Linking perceptual and behavioral customer metrics to multiperiod customer profitability: a comprehensive service-profit chain application. Journal of Service Research, 11(1), 3-21.

Larivière, B., Keiningham, T.L., Aksoy, L., Yalçin, A., Morgeson, F.V.III, \& Mithas, S. (2016). Modeling heterogeinity in the satisfaction, loyalty intention, and shareholder value linkage: A cross-industry analysis at the customer and firm level. Journal of Marketing Research, 53(1), 91-109.

Larivière, B., Joosten, H., Malthouse, E. C., van Birgelen, M., Aksoy, P., Kunz, W. H. \& Huang, M. H. (2013). Value Fusion: The blending of consumer and firm value in the distinct context of mobile technologies and social media. Journal of Service Management, 24(3), 268-293.

Larivière, B. \& Van den Poel, D. (2005). Investigating the post-complaint period by means of survival analysis. Expert Systems with Applications, 29(3), 667-677.

Lee, J. H., Kim, M. S. \& Aeeun, J. (2013). The effects of emotional intelligence on service recovery and organizational loyalty: A case of flight attendants of South Korean Airlines. Service Business, 7(4), 665-686.

Liao, H. (2007). Doing it right this time: The role of employee service recovery performance in customer-perceived justice and customer loyalty after service failures. Journal of Applied Psychology, 92(2), 475-489. 
Maxham, J. G. III. \& Netemeyer, R. G. (2003). Firms Reap What They Sow: The effects of shared values and perceived organizational justice on customers' evaluations of complaint handling. Journal of Marketing, 67(1), 46-62.

Michel, S., Bowen, D. E., \& Johnston, R. (2009). Why service recovery fails: Tensions among the customer, employee and process perspectives. Journal of Service Management, 20(3), 253-273.

National Complaints Culture Survey (2006), The National Complaints Culture Survey, TMI, Reddich.

Orsingher, C., Valentini, S., \& de Angelis, M. (2010). A meta-analysis of satisfaction with complaint handling in services. Journal of the Academy of Marketing Science, 38(2), 169-186.

Ostrom, A., Parasuraman, A., Bowen, D. E., Patricio, L., \& Voss, C. A. (2015). Service research priorities in a rapidly changing context. Journal of Service Research, 18(2), 127159.

Parasuraman, A. (2006). Modeling opportunities in service relationships and customermanaged interactions. Marketing Science, 25(6), 590-593.

Pasmore, W. A. \& Sherwood, J. J. (1978). Sociotechnical Systems: A Sourcebook. LaJolla, CA: University Associates.

Reichers, A. E., Wanous, J. P., \& Austin, J. T. (1997). Understanding and managing cynicism about organizational change. Academy of Management Executive, 11(1), 48-59.

Rod, M. \& Ashill, N. J. (2009). Symptoms of burnout and service recovery performance: The influence of job resourcefulness. Managing Service Quality, 19(1), 60-84.

Rod, M., Ashill, N. J. \& Carruthers, J. (2008). The relationship between job demand stressors, service recovery performance and job outcomes in a state-owned enterprise. Journal of Retailing and Consumer Services, 15(1), 22-31. 
Roschk, H. \& Gelbrich, K. (2014). Identifying appropriate compensation types for service failures: A meta-analytic and experimental analysis. Journal of Service Research, 17(2), 195-210.

Rosenbaum, S. (2015). The brave new world of customer service. Forbes, June 7, http://www.forbes.com/sites/stevenrosenbaum/2015/06/07/the-brave-new-world-ofcustomer-service/\#2715e4857a0ba7324755098f

Salvaggio, A. N., Schneider, B., Nishii, L. H., Mayer, D. M., Ramesh, A., \& Lyon, J. S. (2007). Manager personality, manager service quality orientation, and service climate: test of a model. Journal of Applied Psychology, 92(6), 1741.

Santos-Vijande, M. L., Diaz-Martin, A. M., Suárez-Álvarez, L., \& del Río-Lanza, A. B. (2013). An integrated service recovery system (ISRS): Influence on knowledge-intensive business services performance. European Journal of Marketing, 47(5/6), 934-963.

Schneider, B. (1987). The people make the place. Personnel psychology, 40(3), 437-453.

Sim, K. L., Song, C. J., \& Killough, L. N. (2010). Service quality, service recovery, and financial performance: an analysis of the US airline industry. In: Epstein, M. \& Malina, M. A. (Eds.), Advances in Management Accounting, Volume 18, Emerald Group Publishing Limited Bingley, 27-53.

Smith, A. K., Bolton, R. N. \& Wagner, J. (1999). A model of customer satisfaction with service encounters involving failure and recovery. Journal of Marketing Research, 36(3), $356-372$.

Smith, J. S., Fox, G. L., \& Ramirez, E. (2010). An integrated perspective of service recovery: A socio-technical systems approach. Journal of Service Research, 13(4), 439-452.

Smith, J. S. \& Karwan, K. R. (2010). Empirical profiles of service recovery systems: The maturity perspective. Journal of Service Research, 13(1), 111-125. 
Smith, J. S., Karwan, K. R., \& Markland, R. E. (2009). An empirical examination of the structural dimensions of the service recovery system. Decision Sciences, 40(1), 165-186.

Subramony, M. \& Pugh, S. D. (2015). Services management research: Review, integration, and future directions. Journal of Management, 41(1), 349-373.

Surachartkumtonkun, J., Patterson, P. G. \& McColl-Kennedy, J. R. (2013). Customer rage back-story: Linking needs-based cognitive appraisal to service failure type. Journal of Retailing, 89(1), 72-87.

Tax, S. S. \& Brown, S. W. (1998). Recovering and learning from service failure. Sloan Management Review, 40(1), 75-88.

Tucker, A. L. (2004). The impact of operational failures on hospital nurses and their patients. Journal of Operations Management, 22(2), 151-169.

Tucker, A. L., \& Edmondson, A. C. (2003). Why hospitals don't learn from failures. California Management Review, 45(2), 55-72.

Van den Broeck, A., Van Ruysseveldt, J., Vanbelle, E. \& De Witte, H. (2013). The job demands-resources model: Overview and some suggestions for future research, in Bakker, A. B. (ed.). Advances in Positive Organizational Psychology, Volume 1, Emerald Group Publishing Limited, $83-105$

Van der Heijden, G. A. H., Schepers, J. J. L., Nijssen, E. J., \& Ordanini, A. (2013). Don't just fix it, make it better! Using frontline service employees to improve recovery performance. Journal of the Academy of Marketing Science, 41(5), 515-530.

Van Vaerenbergh, Y., Larivière, B., \& Vermeir, I. (2012). The impact of process recovery communication on customer satisfaction, repurchase intentions, and word-of-mouth intentions. Journal of Service Research, 15(3), 262-279. 
Villarroel Ordenes, F., Burton, J., Theodoulidis, B., Gruber, T., \& Zaki, M. (2014). Analyzing customer experience feedback using text mining: A linguistics-based approach. Journal of Service Research, 17(3), 278-295.

Weitz, B. A. (1981). Effectiveness in sales interactions: A contingency framework. Journal of Marketing, 45(1), 85-103.

Wirtz, J., Tambyah, S. K. \& Mattila, A. S. (2010). Organizational learning from customer feedback received by service employees: A social capital perspective. Journal of Service Management, 21(3), 363-387.

Wong, I. A. (2016). Linking Firms, Employees, and Customers: A multilevel research agenda for hospitality studies. Cornell Hospitality Quarterly, 57(1), 7-20.

Yukl, G. (2012). Effective leadership behavior: What we know and what questions need more attention. Academy of Management Perspectives, 26(4), 66-85. 


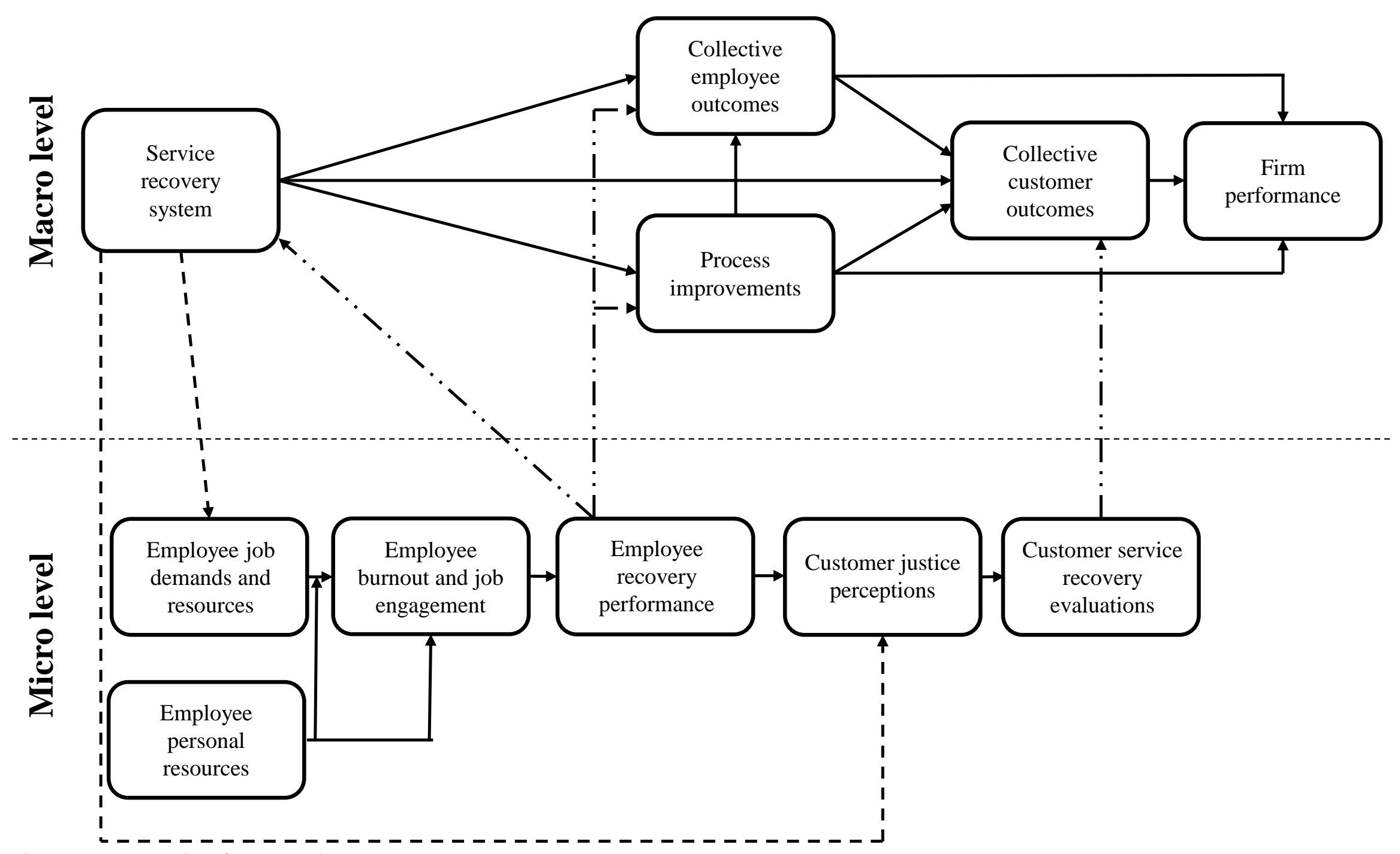

Figure 1. Integrative framework

Notes: Full lines represent within-level linkages, dashed lines represent multilevel effects, dash dot dot lines represent microfoundations. 


\section{Author biographies}

Yves Van Vaerenbergh (yves.vanvaerenbergh@kuleuven.be) is Assistant Professor of Marketing at the KU Leuven, Belgium. He received his Ph.D. in Applied Economics from the Center for Service Intelligence, Ghent University. His research interests include service failure and recovery, meta-analysis, and the role of language in service encounters, among others. He received several best reviewer awards and best paper awards from service journals.

Chiara Orsingher (chiara.orsingher@unibo.it) is Associate Professor of Marketing at the University of Bologna, Italy. She received her Ph.D. in Management Science from the Institut d'Administration des Entreprises of Aix-en-Provence (France). Her research interests include service failure and recovery, meta-analysis, and referral reward programs. Her work has appeared in leading services marketing journals. 